\title{
Conventional Controller Design for Switched Reluctance Motor Drives
}

\author{
J. Uma \\ Senior Assistant Professor \\ Electronics and Instrumentation Engineering \\ M.Kumarasamy College of Engineering \\ Thalavapalayam, Karur-639113, TN, India
}

\author{
A. Jeevanandham \\ Professor \\ Electrical \& Electronics Engineering \\ Bannari Amman Institute of Technology \\ Sathyamangalam, Erode-638401,TN,India
}

\begin{abstract}
This paper proposed a proportional Integral Controller for Switched Reluctance Motor Drive.PI controller is one of the conventional controller. The basic sensorless operation of the Switched Reluctance Motor Drive is usually tested by this conventional controller under steady state condition. The parameter speed of the drive is controlled and analysed with the help of this controller without any position sensor. Instead of position sensor, the speed can be indirectly measured with the help of phasor current and voltage as the input for the controller. The simulation results of the proposed controller validates that the PI controller is best suited for basic sensorless operation under steady state condition.
\end{abstract}

\section{Keywords}

PI controller,SRM,phasor current and voltage.

\section{INTRODUCTION}

Switched Reluctance Motor Drives is one of the special electrical machines available for adjustable speed drives and electric vehicle applications at cheaper cost. Since the Switched Reluctance Motor Drive has no rotor winding it seems to be cheaper but sensor needed for sensing the position makes it costly and complex. Sensing the position of high speed application makes the drive bulky and costlier. Instead of sensing position directly, indirect way of sensing or calculating the position is almost used recently for compact and cheaper drive. In this paper[1] author developed the algorithm to automate and integrate flux linkage characteristics as part of the sensor less controller. The paper [2] proposed a controller to reduce torque ripple even under worst condition the drive is tested with the help of external disturbances. In these proposed paper[3],[4] the author implement the PI controller for four phase Switched Reluctance Motor Drive with rotor position sensor and Neural Network based Controller for four phase Switched Reluctance Motor Drive. It has Port Controlled Hamiltonian $(\mathrm{PCH})$ is inner loop and Passivity Based Robust Adaptive Control (PBRAC) in outer loop. The author [5] proposed how to measure the flux linkage and inductance of phase winding for accurate results over the entire speed range. The obtained test results are validated by applying into submersible pump. These papers[6],[7] describes the design, modeling and control of Switched Reluctance Motor Drive using DSP processor for steady state conditions only the problem of harmonics not to be considered, in these papers a novel method of torque closed loop control and fuzzy compensation control based on finite element model for SRM drive is described. In these [8],[9],[10] papers a new sensor less control scheme using finite element package
MAXWELL has been explained and it is compared with sensor mode.

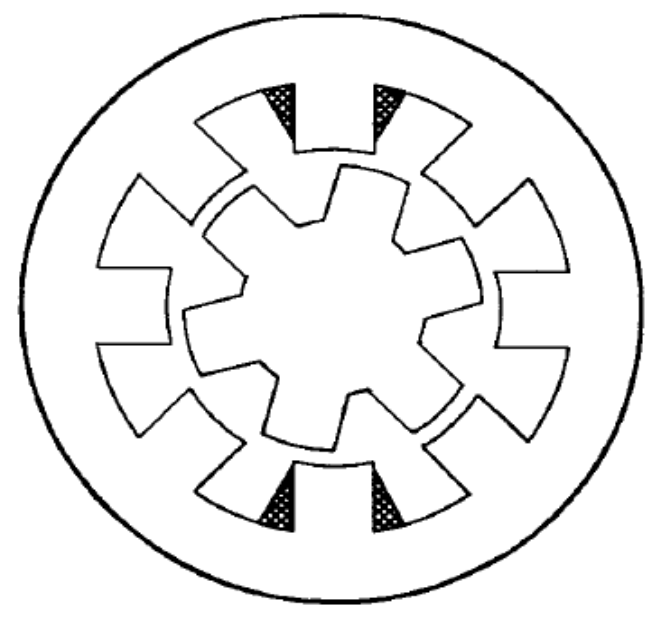

Figure 1: 8/6 Switched Reluctance Motor configuration

The Switched Reluctance Motor is a doubly salient machine with no rotor windings. It has only stator windings make the drive cheaper in cost. The stator poles are excited sequentially attracts the rotor and torque gets produced. The SRM is available in various configuration like $8 / 6,6 / 4,4 / 4,2 / 2$.In the most of the applications like electric vehicles $8 / 6$ type is used.

\section{BASIC PRINCIPLES OF OPERATION}

The phase voltage equation in a Switched Reluctance Motor can be written as [11]

$$
V=i R+\frac{d \lambda}{d t}
$$

Equation 1

Where $\mathrm{V}$ is the dc bus voltage, $\mathrm{i}$ is the instantaneous phase current is the phase winding resistance and $\lambda$ is the flux linking of the phase coil.Ignoring stator resistance, equation 1 can be rewritten as

$$
V=L(\theta) \frac{d i}{d t}+i \frac{d L(\theta)}{d \theta}(\theta)
$$

Where $\omega$ is the rotor speed, $\theta$ is the rotor angular position and $L(\theta)$ is the instantaneous phase inductance. The rate of flow of energy can be obtained by multiplying the voltage with the current and current can be written as [11] 


$$
\mathrm{Vi}=\mathrm{Li} \frac{\mathrm{di}}{\mathrm{dt}}+\mathrm{i}^{2} \frac{\mathrm{dL}}{\mathrm{d} \theta}(1)
$$

Equation 3

or

$$
P=\frac{d}{d t}\left(\frac{1}{2} \mathrm{Li}^{2}\right)+\frac{1}{2} \mathrm{i}^{2} \frac{\mathrm{dL}}{\mathrm{d} \theta}(1)
$$

The first term of the above equation represents the rate of increase in the stored magnetic field energy while the second term is the mechanical output. Thus the instantaneous torque can be [11]

$$
\begin{aligned}
& T(\theta, i)=\frac{1}{2} i^{2} \frac{d L}{d \theta} \\
& T(\theta, i)=\frac{1}{2} i^{2} \frac{d L}{d \theta}
\end{aligned}
$$
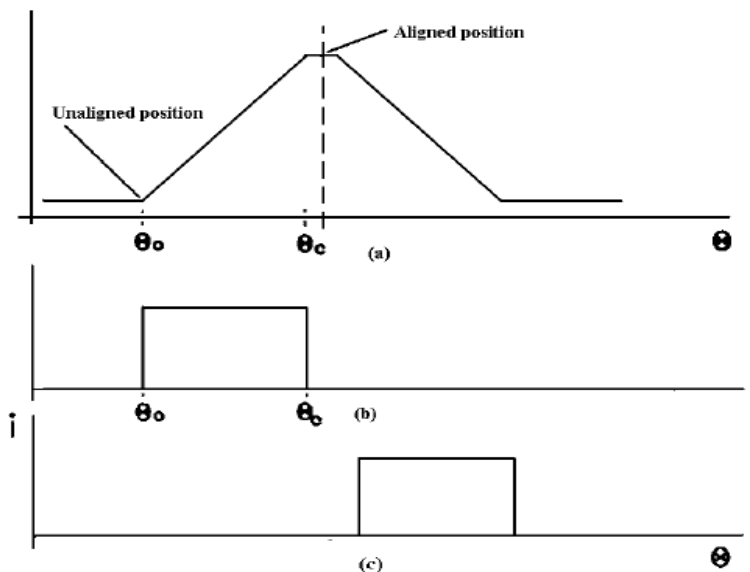

Figure 2: Inductance Profile of an SR motor,(a) variation of inductance with rotor position,(b)Phase current for motoring operation,(c)Phase current for generating operation[11].

\section{CONVERTER TOPOLOGIES}

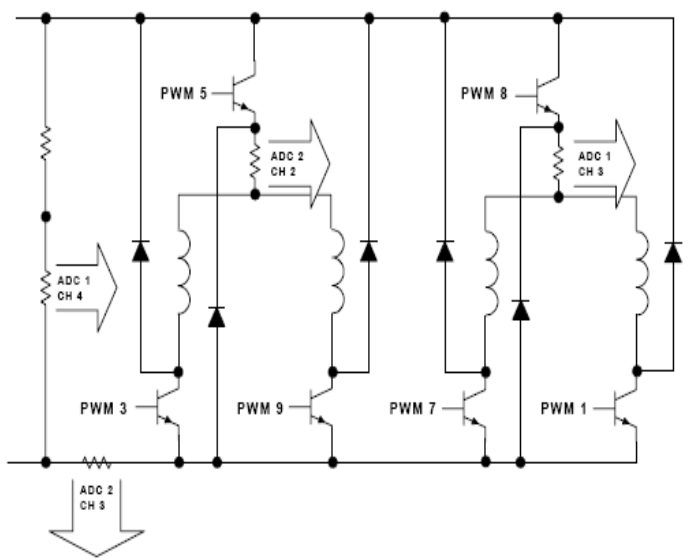

Figure 3: Power Converter of a Switched Reluctance Motor Drive [11]
The unipolar nature of current signal and electrical isolation between phases in SRM makes the various kinds of topologies in converters as best one. Among the various topologies, for effective operation consider the reliable and flexible converters under worst conditions instead of its cost. Generally a converter with less number of switches has less ability to isolate faults in the drive system. Considering the above all points bridge converters as shown in Figure. 3 is the best suitable converters. It has two power switches and two diodes per phase. So the circuit allows control of each phase windings independently. The phase overlap under overloaded conditions in the bridge converter reduces the torque ripples comparatively. The application like electric vehicle, propulsion prefers the bridge converters in the drive system.

Block Diagram of the Switched Reluctance Motor Drive:

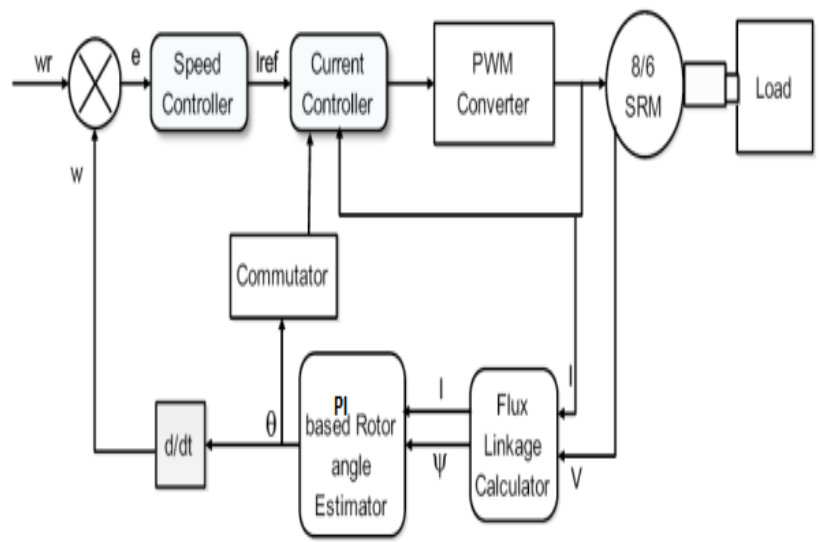

Figure 4: Block Diagram of the Switched Reluctance Motor Drive

The Figure.4 shows the proposed block diagram for the sensorless operation to obtain the speed control with the help of proportional integral (PI) controller. The SRM with eddy current load is connected, the phasor current and voltage is taken as the input for the controller. From the voltage and current signal, the flux linkage characteristics are calculated. From the mapping of look up table corresponding rotor angle is estimated from the characteristics curve. With the help of PI controller the estimated rotor angles is processed and send as the reference signal for the speed controller. After that another PI control module is used to determine the current signal from the current controller module. From the calculated current signal and turn off time, the corresponding signal of pulse for the driver circuit of exact phase is determined. A current control loop provides protection to prevent the current from running away during low winding impedance interval. The speed loop provides reference command for the current loop. 


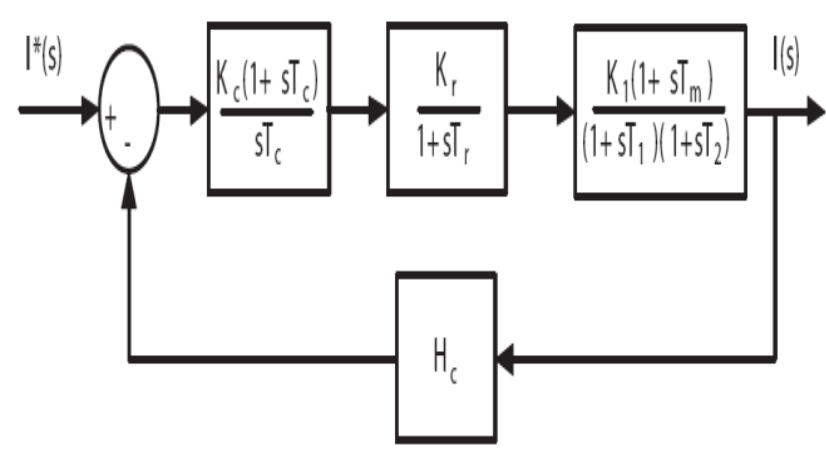

a)

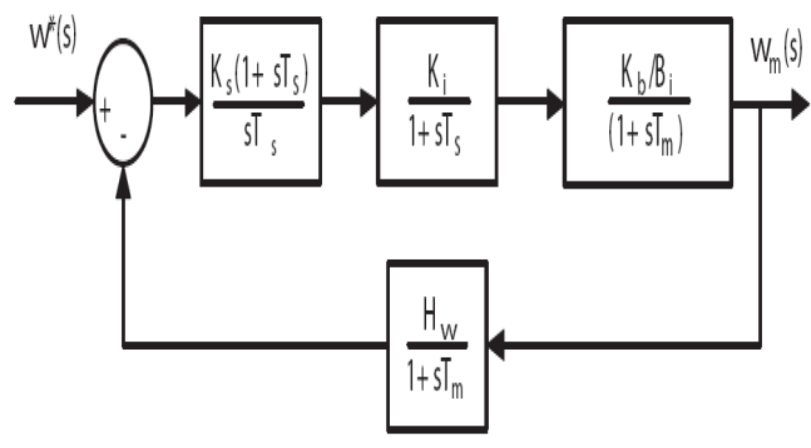

b)

Figure 5: Simplified Speed and Current Controller Loop

Switched Reluctance Motor dynamics are highly non linear. However linear approximations of the motor and converter provides an acceptable mean to develop linear feedback control .The current and speed controller are implemented in this drive with the help of Proportional -Integral Controller(PI).The control parameters of the conventional proportional integral controller were obtained with Cohen and Coon (CC) controller tuning method. The proposed PI controller holds good for steady state operation of the drive under linear condition. The steady state error $(2 \mathrm{rad} / \mathrm{sec})$ produced even after fine tuning was made. The system output responses using the PI controller algorithm produces small dips before reaching the steady state.

\section{NUMERICAL SIMULATIONS}

The proposed controller design of Switched Reluctance Motor Drive is simulated and analysed with the help of MATLAB /Simulink Software. The specifications of the Switched Reluctance Motor is given in the Table.1.The configuration prescribed is mostly used for different kind of applications of the SRM drive. Along with that eddy current damping load is connected to the drive to analyze the controller performance under different value of load conditions.
Table 1. Load specifications for controller performance analysis

\begin{tabular}{|c|c|}
\hline Parameter & Specifications \\
\hline Phase & 4 \\
\hline Stator pole number & 8 \\
\hline Rotor pole number & 6 \\
\hline Rated Voltage & $230 \mathrm{~V}$ \\
\hline Rated current & $10 \mathrm{~A}$ \\
\hline Rated speed & $400 \mathrm{rpm}$ \\
\hline Rated load & $0.75 \mathrm{Kw}$ \\
\hline Moment of inertia $(\mathrm{Jm})$ & $0.005 \mathrm{Kg}-\mathrm{m}^{3}$ \\
\hline Viscous friction coefficient $(\mathrm{Bm})$ & $0.005 \mathrm{Nm} /(\mathrm{rad} / \mathrm{s})$ \\
\hline Stator resistance $\left(\mathrm{R}_{\mathrm{k}}\right)$ & $50 \mathrm{~m}-\mathrm{ohm}$ \\
\hline
\end{tabular}

\section{RESULT AND DISCUSSION}
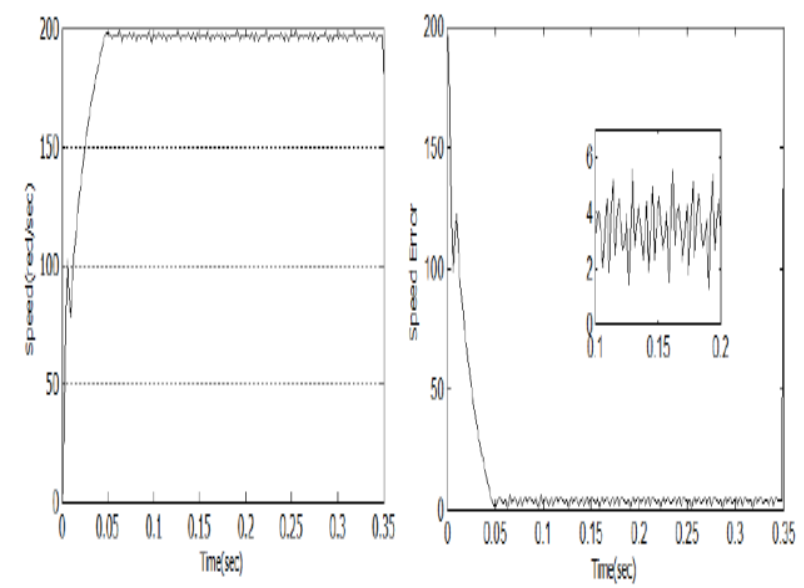

(a)
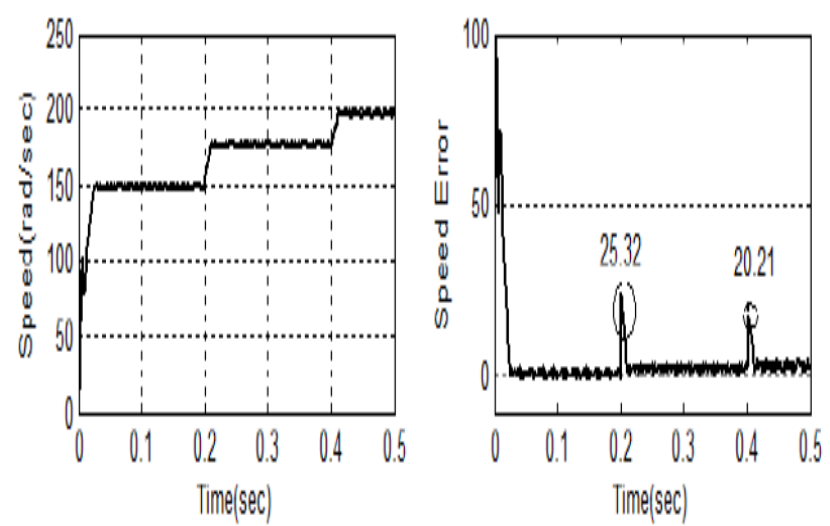

Figure 6: (a)Simulation Results at $200 \mathrm{rad} / \mathrm{sec},(\mathrm{b})$ at different set point conditions $0.2 \mathrm{~s}(100-180 \mathrm{rad} / \mathrm{sec}), 0.4$ $\mathrm{s}(180-200 \mathrm{rad} / \mathrm{sec})$. 

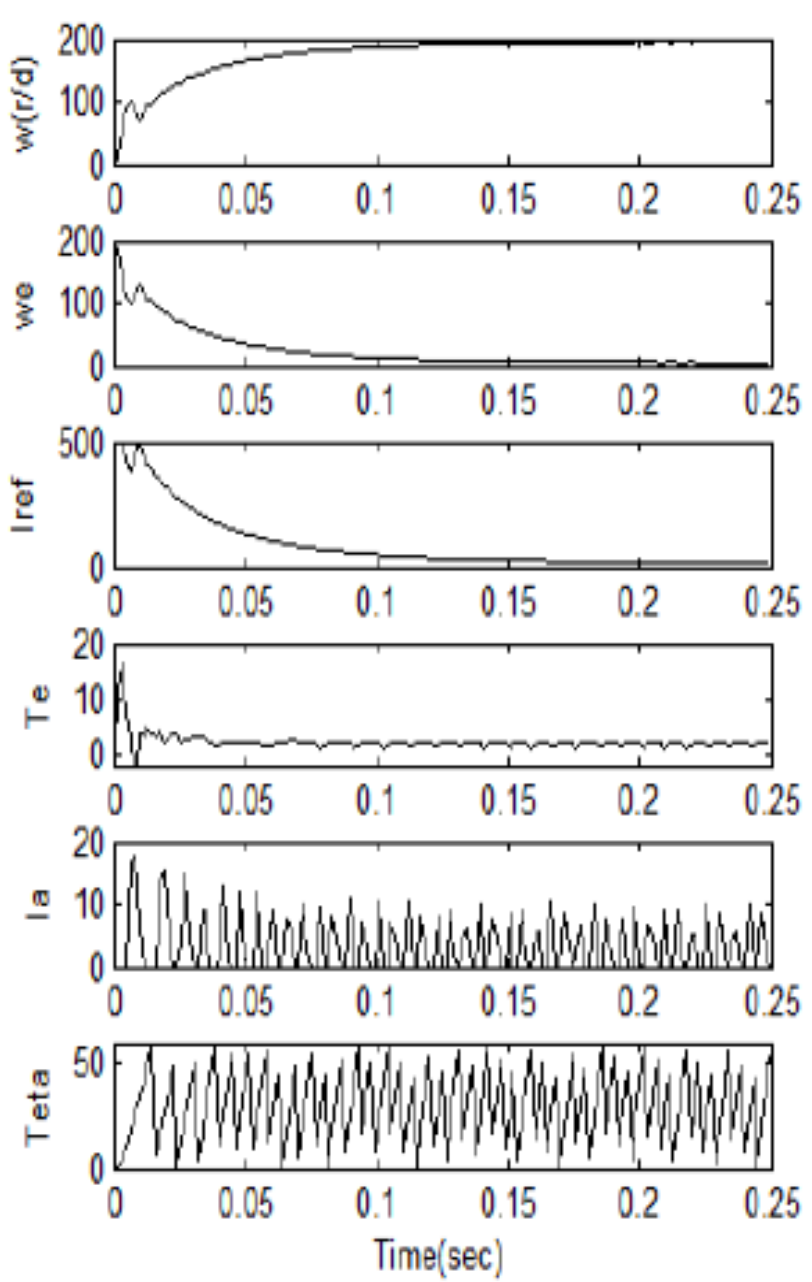

Figure 7: Simulations Results under Full Load Conditions.

To validate the performance of the drive with the help of Proportional Integral controller in a four phase Switched Reluctance Motor Drive were shown. The drive was operated at $200 \mathrm{rad} / \mathrm{sec}$ with external load $\mathrm{T}_{\mathrm{L}}=1 \mathrm{Nm}$ to verify the steady state performance of the proposed controller Figure 6(a). The system output response using the PI control algorithm show small dips before reaching the steady state. The speed changes from 150 to $180 \mathrm{rad} / \mathrm{sec}$ at $0.2 \mathrm{sec}$ and 180 to $200 \mathrm{rad} / \mathrm{sec}$ at $0.4 \mathrm{sec}$ has been shown with speed errors at transient time were shown in the Figure 6(b) simulation output.Figure.7 shows the parameters of actual current, reference current, speed at reference and actual under full load conditions.

\section{CONCLUSION}

The proposed controller performs the effective operation under different values of load condition. The Proportional Integral controller is the best suited controller for linearization of the Switched Reluctance Motor Drive. The system reaches the steady state after certain period of time. The steady state error is admissible one for the normal operation of the drive under low speed operation. The speed shows small dips under initial conditions only. The performance of the drive can be improved with the help of hybrid controller is the future scope of the paper. The hybrid controller can be designed with the help of fuzzy logic ,neural network ,inference system to obtain the optimized result under dynamic conditions. The situations of sudden loading and unloading to be withstand by the controller like hybrid not by the pure PI controller.

\section{REFERENCES}

[1] Debiprasad Panda,V.Ramanarayanan,IEEE,2000,

[2] pp.1569-1574, "Sensorless control of SRM drive with self measured flux linkage characteristics."

[3] M.M.Namazi,S.M.Saghaiannejad and A.Rashidi,International Journal of Electrical and Electronics Engineering 2011, "Torque Ripple Minimization in Switched Reluctance Motor using Passivity Based Robust Adaptive Control."

[4] Mehala.N,Muniraj.C, "Implementation of PI controller for $4 \phi$ SRM drive using TMS320F28335,"International Journal of Power Electronics and Drive Systems(IJPEDS),Vol.5,No.3,pp.283-292, February 2015.

[5] Muniraj.C and Chandrasekar.S, "Neural Network Based Speed Control for 6/4 Switched Reluctance Motor," Conference on Computational Intelligence and Multimedia Applications, 2007

[6] Rakesh Saxena,Bhim Singh and Yogesh Pahariya,International Journal of Computer and Electrical Engineering ,vol.2,No.2,April 2010,pp.389393, "Measurement of Flux Linkage and Inductance Profile of SRM."

[7] Vikas S.Wadnerkar ,Dr.G.Tulasi Ram Das,Dr.A.D.Raj Kumar, Journal of Theoretical and Applied Information Technology,2008, "Performance Analysis of Switched Reluctance Motor :Design,Modeling and Simulation of 8/6 SRM,"pp.1118-1124.

[8] A.Jeevanandham and K.Thanushkodi, "Reduction of Inter Area Oscillations in a Multimachine System Using Swarm Intelligence,'International Transactions on Computer Science and Engineering,Korea.

[9] Haijun Zhang,Jingjun Zhang and Ruizhan Gao,Journal of Computers,vol.4.No.10,October 2009, “A Novel Method of Phase Current Compensation for Switched Reluctance Motor System Based on Finite Element."

[10] G.Bhuvaneswari,Sarit Guka Thakurta,P.Srinivasa Rao and S.S.Murthy,Journal of Power Electronics,vol.6,No.4,October 2006,pp.315-321, "Modeling of a Switched Reluctance Motor in Sensorless and "with sensor" modes."

[11] A.Jeevanandham and K.Thanushkodi, "Reduction of Generator Rotor Oscillations using a Meta-heuristic Optimization Technique," International Journal of Systemics, Cybernetics and Informatics, India, ISSN 0973 -4864, No.9, 2008, pp.54-60.

[12] www.ti.com/lit/an/spra282/spra282.pdf 


\section{AUTHOR PROFILE}

Uma J, Tamil Nadu pursuing research in Power Electronics and Drives, completed post graduate in Power Electronics and Drives, from Annai Mathammal Sheela Engineering College - Anna University Chennai and under graduate in Electrical and Electronics Engineering from Bannari Amman Institute of Technology, Bharathiyar University. She published paper in Refereed Journal -2, National Conference-5 and International Conference -1 with IEEE conference proceedings. Major Fields of interest are Power Electronics and Drives and Electrical Machines. She is currently working as a Senior Assistant Professor in M.Kumarasamy College of Engineering, Karur- Tamil Nadu

Jeevanandham Arumugam, Tamil Nadu completed his under graduation in Electrical and Electronics Engineering from Coimbatore Institute of Technology, Coimbatore and
Post-graduation in Power Systems Engineering from Government College of Technology, Coimbatore. He obtained $\mathrm{PhD}$ in the field of Application of Artificial Intelligence to Power System from Anna University, Chennai. He awarded with PDF in the field of Power System Dynamics from San Diego State University, San Diego, California, USA and PDF in the field of High Solar Penetration from The University of Texas at San Antonio, San Antonio, Texas, USA. He published 18 papers in Refereed Journals, 7 papers in International Conferences and 45 papers in National Conferences. At present, he is working as a Professor in the department of Electrical and Electronics Engineering, Bannari Amman Institute of Technology, Sathyamangalam, India. 